\title{
Critical Responses to Faith Development Theory: A Useful Agenda for
}

\section{Change?}

\section{Adrian Coyle*}

Contact details: Dr Adrian Coyle, Department of Psychology, University of Surrey, Guildford, Surrey GU2 7XH, United Kingdom. Email: A.Coyle@surrey.ac.uk; Tel. +44 (0)1483 686896

ADRIAN COYLE is Senior Lecturer in the Department of Psychology at the University of Surrey. His research interests lie primarily in the psychology of religion, identity, bereavement and qualitative research methods. He is currently developing an interest in the social psychology and theology/spirituality of inter-faith relations and religious communities.

Word count: 7255 (including abstract and references); Submitted 29 June 2011; revised 5 October 2011

*I would like to express my gratitude to Fr Philip Baxter whose doctoral research first drew my attention to James Fowler's work, to Dr Joanna Collicutt of Ripon College Cuddesdon, Oxford, for her input which inspired this paper, and to two anonymous reviewers for their constructive and valuable feedback on an earlier draft. 


\section{Critical Responses to Faith Development Theory: A Useful Agenda for}

\section{Change?}

\section{ABSTRACT}

Since it was first presented, James Fowler's Faith Development Theory has proven influential in pastoral care/counselling, pastoral/practical theology, spiritual direction and Christian education. However, it has also been subject to substantial critical evaluation. This article reviews the major themes within psychological critiques and considers the agenda provided by these critiques for the theory's future development. Critical themes concern Fowler's understanding of 'faith'; the theory's structural 'logic of development'; its over-emphasis on cognition and consequent lack of attention to emotional/psychodynamic dimensions as processes of transition and transformation; its gender bias and cultural specificity; and its purported difficulty in accommodating postmodern trends in psychology. To address these critiques in a meaningful way, it is proposed that there is a need to embrace alternative existing theories of faith development and spiritual/religious change, to construct a radically revised, process-focused version of Faith Development Theory, and to continue to develop new localized process models of faith development.

\section{KEYWORDS}

Faith Development Theory; meaning-making; process models; religious development; stage structure 


\section{Critical Responses to Faith Development Theory: A Useful Agenda for}

\section{Change?}

\section{INTRODUCTION}

Religious development has been a topic of interest within the psychology of religion from the early days of the domain's history. The most influential framework relevant to religious development that has emerged has been James Fowler's Faith Development Theory. Relatively soon after being presented in an elaborated form in Stages of Faith in 1981, the theory began to attract critical comment. This critical evaluative trend has continued and developed as the theory and its related materials have become enormously popular resources in pastoral care/counselling, pastoral/practical theology, spiritual direction and Christian education, especially in the USA (Streib, 2002). Some current critiques represent restated or modified versions of original ones but new critiques have also emerged from changing perspectives within those disciplines that have claimed some 'ownership' of the theory (with consequent perceived evaluative entitlement), such as (practical) theology and (the) psychology (of religion). This article reviews the major themes of the psychological critiques, including Fowler's responses, and considers how, if at all, these critical themes might offer a useful agenda for the theory's future development. First, though, it is worth sketching the key features of the theory, attending particularly to those that have been the focus of critique. 


\section{FAITH DEVELOPMENT THEORY}

Faith Development Theory has been described by Heywood (2008, p. 263) as offering 'a psychologically based theory of human religious development within the broader framework of a theological anthropology'. The theory's concerns are more than psychological (and Fowler himself is not a psychologist by training). The core concept of 'faith' is understood as 'a generic human phenomenon - a way of leaning into or meeting life, whether traditionally religious, or Christian, or not' (Fowler, 1986, p. 16). This understanding of faith as a universal human concern, held to be a component of every religion but antecedent to being religious or irreligious, might appear to represent an attempt to reach beyond a theological audience. Yet Fowler was drawing here upon the theologian-ethicist H. Richard Niebuhr's (1960) conceptualization of faith, but he was also influenced by the ideas of the theologian-philosopher, Paul Tillich and the scholar of comparative religion, Wilfred Cantwell Smith. In essence, Niebuhr regarded faith as a universal human process that involves people trying to find meaning in their lives by placing their trust and loyalty in some attractive centre(s) of value that represent(s) for them a reality that is sustaining, reliable and dependable.

Such an all-encompassing understanding of faith required Fowler to adopt a multiperspective approach in his psychological elaboration of it. Hence he created a theoretical matrix for the study of what he saw as the structuring aspects of faith. This consisted originally of seven dimensions or perspectives, later extended to eight (see Moseley, Jarvis, \& Fowler, 1993), comprising perspectives on 'form of logic' or cognitive development (drawn from Piaget); the development of the capacity to take the perspectives of others; the development of moral judgment/reasoning (from Kohlberg); the recognition of others as belonging to one's faith community; the selection of authorities for meaning-making; 'form of world coherence' or the 
development of approaches for 'unifying meanings' (from Erikson's and Levinson's lifespan developmental theories); the understanding of symbols and of stages of self (from Kegan). Those that have attracted most attention in commentaries are the perspectives on the development of logical thinking, moral judgment/reasoning and ways of unifying meanings.

These perspectives were applied to data generated from lengthy, structured interviews ('Faith Development Interviews') with people of different ages and from different religious traditions, focused on significant life experiences and the meanings attributed to them (such as evil and suffering; the limits of knowledge; death and afterlife; the purpose of life). Through this, Fowler identified seven stages of faith development stretching across the lifespan. Faith Development Theory is thus located within the category of structural stage theories of development, the classic example of which is Piaget's theory of cognitive development; the other major theories upon which Fowler drew also shared a stage structure (although Levinson, 1978, referred to 'eras' rather than stages). Stage theories (cl)aim to identify and explicate fundamental underlying structures that shape development and that are universal and independent of culture. Such theories assume that development unfolds in sequential and invariant stages, defined by Fowler (1986, p. 27) in his theory as 'the deeper structural operations of knowing and valuing which underlie, ground, and organize the thematic content' of a person's faith.

The theoretical framework begins with 'undifferentiated faith' or 'primal faith' in 'stage zero' (0-3 years) and progresses to 'intuitive-projective faith' in 'stage one' (circa 4-7 years); 'mythic-literal faith' in 'stage two' (circa 7-11 years); 'synthetic-conventional faith' in 'stage three' (circa 11/12-17/18 years, although this is held to last potentially into middle age and possibly into late adulthood); 'individuative-reflective faith' in 'stage four' (the early twenties, thirties or forties); 'conjunctive faith' in 'stage five' (when the Piagetian development of logical 
thought is said to give way to relational and contextual reasoning; this is held to be rarely seen before the age of 30, more usually developing in midlife and beyond, if at all); and 'universalising faith' in 'stage six' (which is believed to be rarely attained but is specified largely to demonstrate the terminus ad quem of his notion of development). Fowler believed that people developed through these stages in accordance with their own individual life circumstances. For a useful summary of the specifics of Faith Development Theory, see Gollnick (2005).

With this elaborate structure, Fowler felt confident that he had devised a theory which could be used to 'map' faith development in any circumstances to aid pastoral, educational and other forms of practice. This is worth noting: as he has said himself, 'It is important to recognize that faith development theory...had its origins in a context of praxis' (Fowler, 2001, p. 159). He believed that he had identified psychological structures that were fundamental to human being and knowing. The theory was modified and qualified in some respects in later years but the central features have remained in place.

\section{CRITICAL RESPONSES TO FAITH DEVELOPMENT THEORY}

Although critical psychological responses to Faith Development Theory have appeared across a range of publications, the major clusters of specific evaluative work can be found in Dykstra and Parks (1986a), Fowler, Nipkow, and Schweitzer (1991), Astley and Francis (1992) and a special issue of the International Journal for the Psychology of Religion (Streib, 2001a). Other critical work has been presented in the context of broader examinations of the psychology of religion and religious development (for example, Reich, 2005, 2008). The 
major themes that have characterized these responses are critiques about its structural 'logic of development'; its over-emphasis on cognition and consequent lack of attention to emotional/psychodynamic dimensions as processes of transition and transformation; its gendered bias and cultural specificity; and its purported difficulty in accommodating postmodern trends in psychology. In addition, criticisms have been levelled at the theory for its relatively insubstantial and methodologically problematic empirical base (for example, Nelson \& Aleshire, 1986; but see Streib, 2004, for a qualified defence), although it has inspired a body of secondary empirical research conducted largely by Fowler's students and collaborators (see Slee, 1996, and Streib, 2005, for reviews). However, this review will begin with what could be said to be the most fundamental critical issue of all: Fowler's understanding of his core concept of 'faith'.

FOWLER'S UNDERSTANDING OF 'FAITH'

Fowler's understanding of 'faith' in terms of meaning has attracted criticism from scholars in theology and religious studies but questions can also be levelled from a psychological perspective. The theological criticisms have centred on the contention that, from an orthodox Christian viewpoint, 'faith' is understood as a human response to God's grace and as a gift from God, whereas Faith Development Theory focuses on the human dimension of faith (see McDargh, 2001, for a concise exposition of this critique). Fowler (1992) confronted this objection and stated that the theory does not aim to deny or replace such understandings. Rather he pointed out that its concern is with understanding the phenomenology of how people develop ways of relating to their world and themselves in light of their understandings of ultimate reality, 
however they conceive that. However, Fowler's assumption that 'faith' is a component of every religion is also questionable: while faith is central within Christian traditions, it is less important or even marginal in other religious traditions which are primarily conceived as ways of being and doing in the world.

The major query that could be raised about Fowler's definition(s) of faith from a psychological perspective concerns its focus on the development of meaning, which overlaps with the foci of a range of other psychological models. For example, Baumeister (1991) conceptualized personal meaning in terms of the fulfilment of needs for purpose, values, efficiency and self-worth. The question must then be raised of whether the type of meaning development examined in Faith Development Theory is sufficiently distinctive to require a specific model or whether it could be readily accommodated within more general models of meaning system change and development. If faith-related meaning development in Fowler's terms is deemed a distinctive category, the question remains of whether it might usefully be incorporated within models of meaning change focused on faith or spirituality which do not embody those other features of Fowler's model that have attracted significant critique (such as Paloutzian's, 2005, 'meaning-system analysis' of spiritual transformation).

\section{THE THEORY'S STRUCTURAL LOGIC OF DEVELOPMENT}

Although critical responses to Faith Development Theory's core concept of 'faith' seem fundamental, the most persistent criticisms concern the theory's structural logic of development, with these featuring in both early and later critiques and being directed also at other structural stage theories of spiritual/religious development such as Oser and Gmünder's (1991) 
conceptualization of the development of 'religious judgement'. The basic problem that critics find with the stage structure is that, as Streib (2001b, p. 144) summarized, it fails to account for 'the rich and deep life-world and life-history-related dimensions of religion'. Fowler (2004, p. 416) claimed that those who use the theory in religious education find that the 'scaffolding' offered by the stage structure is 'helpful in shaping the educational aims involved in teaching and exploring faith traditions'. Whether claims about utility might justify retaining a feature that may be erroneous is doubtful.

One standard concomitant of stage structure has been subjected to qualification as, in the 1990s, Fowler modified his initial confidence about the universal nature of his stages. For example, in the 1995 edition of Stages of Faith, he wrote that 'some stages of faith may be universal despite the great variety... of content' (Fowler, 1995, p. 99, emphasis added). However, he has remained doggedly insistent on the invariance, sequence and hierarchy of stages (for example, see Fowler, 2001) and it is this that has attracted heavy criticism. His insistence is rather surprising, given that the limitations of stage models (and the problems of universal claims) have long been recognized in psychology and are now presented as an accepted outlook in developmental psychology textbooks. For example, Fischer and Bidell (2006, p. 343) concluded their overview of the stage framework by stating that, 'stage theory has provided no explanation for most observed patterns of variation in developmental level, synchrony, and sequence'. Moreover, when Stages of Faith was published, a range of studies were in the public domain that seriously questioned Piaget's theoretical approach and methods (for example, Brainerd, 1978). Furthermore, what is not often appreciated is that Piaget himself moved away from a rigid stage framework in his later work (Miller, 2002). Indeed, he was represented as having considered development more in terms of 'a spiral' (Vuyk, 1981) as his attention shifted to processes of cognitive change, especially the 
equilibration process and its sub-processes of assimilation, accommodation, feedback from actions and the reorganization of lower-level knowledge at higher levels. Fowler (1995, p. 274) too conceptualizes the relationship between stages in terms of a 'rising spiral movement' within a model that should be imagined as 'at least four-dimensional'. Hence, a close inspection of how Fowler actually represents movement through and across stages reveals much more fluidity than might be expected from his defence of an invariant, sequential and hierarchical stage format. Nevertheless, despite the fluidity in dynamics of inter-stage movement, the fundamental problems with the structural logic of development remain (in both Piaget and Fowler). This potentially misrepresents the actualities of faith development and the normative associations that accompany any stage model could lead to a rigidity and unhelpful judgmentalism when informing pastoral or educational practice.

When Fowler was developing his theory, it is not as if there were no other potentially more credible and useful formats available for modelling psychological phenomena that involve change and development, such as a focus on process. To take one 'extreme case', just five years after the publication of Stages of Faith, Breakwell (1986) presented her initial elaborated exposition of what subsequently became known as identity process theory. In this work, she explicitly rejected the option of focusing her theory on specific identity content (just as Fowler did in relation to the specific content of faith) or (unlike Fowler in the main) on structural features. Instead, she opted to concentrate on what she assumed to be the universal identity processes (assimilation-accommodation - note the Piagetian debt - and evaluation) that she believed determined the 'shape' and content of identity change in response to threat. The focus on macro-processes conferred flexibility on the theory which has subsequently allowed it to be applied to and offer psychological insights into a variety of specific identity contexts, including religious identity (for example, see Coyle \& Rafalin, 
2000; Jaspal \& Cinnirella, 2010). An approach to faith development that accords significant attention to process is feasible, as demonstrated, for example, by Slee's (2004) research on women's faith development. Here processes of conversational, metaphoric, narrative, personalized, conceptual and apophatic 'faithing' are highlighted.

Of course, in drawing upon Piaget, Fowler drew upon a framework that, as noted above, is predicated upon processes of cognitive change. If Faith Development Theory's stage structure were to be abandoned, (selected) processes of assimilation, accommodation, feedback from actions and the reorganization of lower-level knowledge at higher levels could be moved to the heart of the model as its defining features. This would carry an additional advantage of simplifying and rendering more coherent a model that was complex to begin with and has become over-complicated in recent years as it has sought to respond to criticisms (for example, in 2001, Fowler suggested supplementing the stages with the concept of 'faith types'). It also avoids the over-complicating nature of less radical suggested revisions to the theory, such as Streib's (2001b) addition of 'religious styles'. The simplification and greater coherence would stem from elaborating the process connotations of Fowler's conceptualization of inter-stage movement, and extending these same processes to account for the types of features that presently appear within the stages of faith but without arranging processes or features in a necessary sequence or hierarchy.

In order to convey what a process-focused approach to faith development might look like in more specific terms, it may be useful to apply it to an example:

Steve is a man in his forties who, from early adulthood, has invested his energies heavily in his career, which is central to his sense of identity and self-worth. Steve married in his late twenties and has two children, although his marriage ended in divorce five years ago. He describes the end of his marriage as 'complex' but 
acknowledges that too often his wife and family did not even play a secondary role in his priorities. Religion did not feature significantly in Steve's upbringing but his exwife identified as Christian and attended church with the children most Sundays. Steve also attended with her early in his marriage because he thought his wife would appreciate it but, as time went on and as job demands increased, this became more intermittent and then ceased.

A year ago, the company which had employed Steve for the previous eight years experienced major financial difficulties and, with no immediate prospect of an economic 'up-turn', Steve was one of many employees at middle management level who were made redundant. This came as a huge shock to him and he has struggled to accept the reality of his job loss. He has been unable to secure a new job despite having applied for many jobs that seemed suited to his skills and experience. Over the past year, his sense of well-being has fluctuated greatly, with periods of anxiety, depression, 'emptiness', anger and loneliness (he has been unwilling to seek support from former colleagues who were also made redundant) interspersed with times of hope when he applied for new jobs only for this to be dashed with each failure to secure a new job.

His ex-wife asked him to spend more time looking after their children now that he has more time. At first he did this with reluctance and some resentment. However, in recent weeks, Steve feels he has begun to 'turn a corner'. He is enjoying spending time with his children and has also accompanied them to church with his exwife. He has begun to reflect on his life to date, critically evaluate his priorities and his sources of value, and wonder about the purpose of his life, including, to his surprise, the 'God stuff'. He still experiences low mood at times and anxiety about the 
future but he is also able to see what he has in his life and wonder about what he could have.

Different aspects of this vignette could locate Steve at different stages within Fowler's model (for example, there are elements of 'synthetic-conventional faith' and 'individuativereflective faith'), although the information provided here falls far short of the amount of information yielded by a Faith Development Interview. Rather than trying to locate Steve within the theory, though, here we shall consider the vignette more openly in terms of process.

The pivotal event in this vignette is Steve's job loss. His job seems to have been his primary locus of 'faith', that is, his value centre, his focus of loyalty and his chief source of meaning. This locus of faith was not religiously oriented: indeed, his engagement with religious practice during his marriage could be described as extrinsically motivated (Allport \& Ross, 1967). The unexpected loss of his job represented a major psychological and social loss which has proved difficult to accept and which may have led him to question his investment of trust and loyalty there. The magnitude, negative valence and implications of this loss may make it difficult to assimilate. Extensive reworking of the content and structure of his faith (and identity) commitments may be needed before it can be accommodated. Although Steve's search for a new job is undoubtedly motivated by practical concerns, this could also be understood as an attempt to repair and re-establish his former faith structure and carry on with his life as before, assuming that he has searched for a position similar in status, income and demands to his former job. His alignment with his former faith commitments can be seen in his initially negative response to the request from his ex-wife to spend more time with their children: the non-occupational, relational focus that this requires locates him outside his former centre of commitment and meaning. 
However, his engagement with this may have had some catalytic or crystallizing effect upon the process of change (perhaps as an instance of feedback from actions) as he describes himself in transformational terms as having begun to 'turn a corner'. Note that the change is emergent: he has begun and still experiences painful psychological states 'at times'. The profound reflective questioning in which he is engaging may represent the accommodation process in that space is being opened up within the previous faith structure (perhaps through the attribution of new valence to and the reorganization of existing components) to permit the assimilation of a new reality and the emergence of a revised, broader, pluralist centre of faith. This new faith position may include a religious component or what he terms the 'God stuff', the impetus for which may be unknown to him and perhaps unconscious, indicated by his reported sense of surprise.

Of course what we see here is an emergent change, the future course of which may be difficult to predict. For example, Steve may engage actively with this unfolding shift in focus or at least may not seek to block it; if the macro-economic situation were to improve and he were able to secure a new job that was similar to his former job, he could embrace what may feel like a return to familiar, safe territory and set aside the emergent change; or he could seek to integrate former and emergent faith commitments in a workable, satisfying synthesis.

TREATMENT OF TRANSFORMATION

Related to the critique of structural logic is the accusation of relative inattention to conditions and processes of transformation in Faith Development Theory (see Rizzuto, 2001, for example). Although such accusations constitute a common critique of developmental theories 
(for example, see Miller, 2002, pp. 452-454), they seem a little curious here, given that Fowler does attend to this dimension and subsequent researchers have suggested further elaborations of transition processes, drawing again on Piaget. For example, Hamrick (1988) suggested four sequential periods in moving from one stage to another, involving disequilibrium and disengagement from the dominant stage; expansion and exploration, involving new contexts, influential individuals, spiritual insights and reflection; focusing and equilibrium, associated with formal educational input; and reintegration and involvement with/commitment to the new structure of faith. Nonetheless, if Fowler were to adopt a more thoroughly process-based approach, this would necessarily place mechanisms of change (and maintenance) at the heart of the theory, as in our consideration of the vignette about Steve. Focusing on processes of faith development might be resisted on the grounds that it could entail a potentially problematic further shift away from specificity within a theory which has attracted criticism for its lack of specificity about what it understands by its core concern of 'faith'. This is not inevitable: indeed, a more specific definition of core concerns could result if 'faith' and 'faith development' were redefined in terms of a revised model's central processes, as Breakwell (1986, pp. 46-47) did in her process-based definition of 'identity threat', which was her core concern. For example, a core concern could be with pressures for change or 'threats' to the maintenance of a current faith position, with these experienced as negative or positive. Pressures for change or 'faith threats' could be understood as circumstances in which processes of faith (potentially assimilation, accommodation, feedback from actions and/or the reorganization of lower-level knowledge at higher levels) are unable to orient towards the goals of faith development, however they might be understood. This situation stimulates psychological, behavioural, social and/or spiritual 'action' in response to the pressures for change or 'faith threats'. Steve's job loss could therefore be seen in terms of 'faith threat', with his initial responses being oriented towards restitution of the status quo and later responses 
representing processes that seem oriented towards a revision of the nature and organization of faith commitments and even the goals of faith development.

One notable feature of the calls for increased attention to processes of transformation is that the processes that critics wish to see attended to are generally emotion-focused (reflecting observations that the theory is more oriented towards cognition), framed in psychodynamic terms. For example, McDargh (2001, p. 189) posed questions that he believed the theory cannot adequately answer without invoking emotion-focused psychodynamic processes. For instance, he asked, 'why is it that some persons seem to get stuck in particular positions or stages and hold on tenaciously to modes of meaning-making that seem to be self-defeating and that no longer work for them?' Fowler's under-emphasis of psychodynamic processes may be partly due to a desire for Faith Development Theory to lend itself readily to empirical exploration, although credible strategies for researching psychodynamic processes (often qualitatively) have existed for some time (for example, Dahl, Kächele, \& Thomä, 1988). The merits of incorporating psychodynamic processes are difficult to assess because, while they might increase the scope of the theory and perhaps its pastoral utility, they would risk further complicating a theory that could, in trying to appease all critics, collapse under an ambition to become a 'theory of everything'.

GENDER AND CULTURAL SPECIFICITY

Just as the androcentric focus of Kohlberg's stages of moral reasoning/development was critiqued by Gilligan (1982), so questions have been raised about whether Faith Development Theory applies equally to men and women. Slee (2004) has pointed to empirical studies 
which have shown that women score less highly on Faith Development Interviews than men and that women proceed to the more 'advanced' stages of faith development at later ages. Fowler (1992) himself has conceded an element of under-scoring for women and overscoring for men and has suggested the inclusion of 'relational knowing' (reflecting Gilligan, 1982 ) in the fourth stage (Fowler, 2000). However, there has been no reworking of the sequence of stages and so Slee (2004, p. 32) concluded that 'women's distinctive patterns of faith may not adequately be accounted for by his stages', highlighting particularly the middle stages with their general pattern of movement towards separation and autonomy, which does not reflect the emphasis on relationality that has (perhaps overly) characterized work on women's development since Gilligan. Given the criticisms that have been levelled at the theory's stage structure both from outside and within feminist perspectives, something more than tinkering with this structure is required. Some feminist work on faith development has used the notion of stages as fluid, dynamic, non-hierarchical phases or steps shaped by emotion, imagination and relationship as well as by cognition (for example, see Harris, 1989) or has eschewed stages altogether (as in Slee's, 2004, model). If we were to return to the vignette about Steve and replace 'Steve' with 'Stephanie', her position and the dilemmas that she faces would be quite different because her job loss would be framed and experienced against social representations of women and work and of women and family, which may influence the processes and nature of change quite differently, underlining the need for flexibility and openness within models of faith development.

Faith Development Theory has also been accused of cultural specificity, despite Fowler's (2001) emphasis that, in influencing a person's worldview, the structuring power of his stages operates alongside the structuring power of the cultural environment. Baxter (2006) observed that Fowler's initial formulation and subsequent refinements of his core concept of 
'faith' occurred within the context of the concerns and questions of late twentieth century Euro-American intellectual culture. For example, deLaurentis $(1985$, p. 78$)$ contended that Faith Development Theory is concerned with 'the faith of the radical monotheist' (although a softening of this can be discerned in the first chapter of Faithful Change in 1996). Baxter (2006, pp. 103-104) has contended that, from a Vygotskian perspective, the Piagetian core of Faith Development Theory can be said to have failed to consider the constitutive role of engagement in cultural life for forging mental contents and operations. He maintains that this weakness becomes 'all the more weighty' when the theory is exported from its Western context of origin and is applied in other cultural contexts, his particular concern being with African contexts. Baxter acknowledges that, over the course of his work on faith development, Fowler usefully reworked the theological synthesis that informs Faith Development Theory. However, he deems it to be of limited utility transculturally until the psychological synthesis is similarly reworked. The suggestions for reworking that he offers draw upon resources from postmodern psychology, with its recognition of the validity and value of a plurality of viewpoints and different types of discourse.

(LACK OF) OPENNESS TO POSTMODERN PERSPECTIVES

However, relevant to this suggestion and linked to the concern with process is the criticism that Faith Development Theory cannot easily accommodate a postmodern sensibility which, among other features, is characterized by movement from objectivity and meta-narratives to a socially constructed world of plural realities and local narratives (Gergen, 2001). Faith Development Theory has been represented as a modernist endeavour because of its aspiration 
to universalism (later qualified), its separation of form and content, its conceptualization of human experience in ordered stages and its aim of being grounded in empirical evidence (Heywood, 2008). From the outset, there was an inbuilt tension between Faith Development Theory and a postmodern perspective as, in the first edition of Stages of Faith, Fowler (1981, p. 15) stated that he wrote the book in order to reject the relativist view that religious claims and experience have no necessary validity beyond the limits of the communities that hold them (for more on postmodernism, linked explicitly to religion, see Gellner, 1992; Grenz, 1996). This was later reinterpreted by the Fowlerian educationalists, Dykstra and Parks (1986b), who saw him as embracing pluralism, that is, the position that there is a legitimate range of views on any matter, though some are more persuasive and reasonable than others. He himself engaged theologically with postmodernism in Faithful Change (Fowler, 1996) where he considered theological strategies for addressing postmodern conditions and consciousness. Here and elsewhere (for example, see Fowler, 1987), he could be seen as engaging with questions of the unitary/plurality of self as he considers experiences of change, growth, and transitions. Yet he engages with the questions raised by postmodernism within the terms of his modernist theory, thereby avoiding the critical implications that an engagement with these questions on their own terms might bring for the theory (for example, in terms of a plurality of trajectories through faith development involving a not-necessarilyproblematic apparent lack of consistency or coherence), and he has shown no more recent willingness to face these questions (Fowler, 2001, 2004). This is understandable in some respects as to do so could destroy the rationale for the theory's structuralist commitment but in other respects it is more puzzling as the theory's theological roots (that is, the Niebuhrian emphasis on knowledge arising from shared meaning-making in community) offer a basis for constructive engagement with postmodernism (Heywood, 2008). 


\section{CONCLUSION: AN AGENDA FOR THE FUTURE}

Any consideration of critical responses to Faith Development Theory risks overlooking or under-playing the magnitude of Fowler's contribution to advancing and enriching conceptualizations of the development of faith or religious judgment, which becomes especially clear when viewed in historical and inter-disciplinary context. For example, Slee (2004) has acknowledged that the lifespan orientation of Fowler (and Oser and colleagues) represented an advance on earlier work on religious development which focused on childhood and adolescence (such as Goldman, 1964) and that Fowler modelled possibilities for enriching the cognitivedevelopmental tradition through his incorporation of insights from Erikson's and Levinson's psychodynamic models of development. As noted in the introduction, Faith Development Theory has been enormously influential in a range of applied religious-related domains. If the theory is mistaken about some fundamental aspects of faith development, the implications for pastoral and educational practice of not proclaiming its shortcomings to diverse audiences in ways that can be heard and used may be very serious.

This consideration returns us to the focal question of whether critical responses to Faith Development Theory offer a useful agenda for change, specifically in relation to the theory's future development. Given the extent of the criticisms about some fundamental aspects of the theory (especially the stage structure and its invariant, sequential and hierarchical nature) and Fowler's failure to engage with these criticisms in a concerted way, Heywood's (2008, p. 270) suggestion that Faith Development Theory 'is an example of a paradigm reaching the end of its life' does not sound like an overstatement. Hence the critical responses to the theory may be 
seen as not so much offering an agenda for developing the theory as routes for developing the study of its focal concerns outside the theory and separate from Fowler. As Heywood (2008, p. 264) has pointed out:

The abandonment of Fowler's explanation for what he calls 'faith development' does not entail abandoning the observation that people construct the meaning of their lives and faith in different ways, that these constructions may change in significant ways during the course of their lives, nor that they display regularities which may profitably be compared. It does not entail a denial that there is something there to be explained, only that Fowler's explanation is not the correct one.

With this in mind, the main options seem to be to replace Faith Development Theory with general theories of meaning change or with (perhaps revised) alternative theories of faith development or spiritual/religious change that do not share its deficiencies (for example, Reich's, 2003, dynamic, non-stage-based model of the person-God relationship); to revise Faith Development Theory radically by abandoning the stage structure and focusing on processes of faith development (potentially including psychodynamic processes) ; or to continue to build localized process models of faith development, incorporating insights from Fowler where appropriate (following Slee's, 2004, example). These proposals arise from critiques of both the substance and structure of Faith Development Theory.

To rely on general theories of meaning development to account for what Fowler deems faith development would involve accepting his broad understanding of faith. Despite theological criticisms, this has much to recommend it. In a Western culture in which religious faith is increasingly appraised negatively, such an understanding constructs religious faith not as a bizarre phenomenon but as arising from and being an expression of a universal human meaningmaking orientation. It also allows the conceptualization of faith development to draw upon 
theories from the psychological mainstream, reducing the risk of its ghettoization. General theories of meaning development would not necessarily risk under-emphasizing any distinctive features of faith development: their focus on general principles and processes allows ample scope for contextual specification. When applied in religious contexts, they may be most obviously relevant to people whose meaning systems are organized in salient ways around a 'relation-to-the-transcendent' feature rather than religious contexts where ritual and practice are foregrounded over belief (although ritual and practice are necessarily subject to meaning-making too).

The proposals to embrace alternative existing theories of faith development and spiritual/religious change, to construct a radically revised, process-focused version of Faith Development Theory, and to continue to develop new localized process models are not mutually exclusive; new models could be developed to address gaps in the coverage provided by nonstage-based existing models and by the retention of useful Fowlerian insights. Building new localized models would be best enacted through bottom-up theory development of the type found in grounded theory (for a good version of this, see Charmaz, 2006). This would go some way to avoiding the criticisms levelled at Faith Development Theory's empirical basis and it would also fulfil Streib's (2005) call for greater attention to the narrativity of faith, albeit in a more radical way than he suggests. It would also engage seriously with Lyotard's (1984) representation of the postmodern condition in terms of the abandonment of the search for meta-narratives and the valorization of the role of 'little narratives' or localized accounts in lives. This would additionally create conditions for diverse voices (in terms of gender, culture, religious tradition/stance and sexuality, for example) to be heard on their own terms in relation to faith development (or more precisely, as Wilkinson and Kitzinger, 1996, have pointed out, through the considered lens of the researcher). This is not to abandon the 
possibility of accessing universal aspects of faith development but such access would be gained through reflection upon close inspections of a range of particulars. In summary, this represents a call for a different set of theoretical resources and analytic perspectives in the study of faith development in order to permit the complexity of 'the rich and deep life-world and life-history-related dimensions of religion' (Streib, 2001b, p. 144) to be more faithfully heard and understood. 


\section{REFERENCES}

Allport, G. W., \& Ross, J. M. (1967). Personal religious orientation and prejudice. Journal of Personality and Social Psychology, 5, 432-443.

Astley, J., \& Francis, L. (Eds.) (1992). Christian perspectives on faith development. Leominster: Gracewing.

Baumeister, R. F. (1991). Meanings of life. New York: Guilford Press.

Baxter, P. (2006). From Ubuzungu to Ubuntu: Resources for pastoral counselling in a Bantu context. Unpublished $\mathrm{PhD}$ thesis: Kimmage Mission Institute of Theology and Culture, Milltown Institute, Dublin.

Brainerd, C. (1978). Piaget's theory of intelligence. Englewood Cliffs, NJ: Prentice Hall.

Breakwell, G. M. (1986). Coping with threatened identity. London: Methuen.

Charmaz, K. (2006). Constructing grounded theory: A practical guide through qualitative analysis. London: Sage.

Coyle, A., \& Rafalin, D. (2000). Jewish gay men's accounts of negotiating cultural, religious, and sexual identity: A qualitative study. Journal of Psychology \& Human Sexuality, 12(4), 21-48.

Dahl, H., Kächele, H., \& Thomä, H. (Eds) (1988). Psychoanalytic process research strategies. Berlin: Springer-Verlag.

deLaurentis, H. (1985). Maturity of faith: An interdisciplinary clarification of the term. Unpublished thesis: Catholic University of America. 
Dykstra, C., \& Parks, S. (Eds.) (1986a). Faith development and Fowler. Birmingham, AL: Religious Education Press.

Dykstra, C., \& Parks, S. (1986b). Introduction. In C. Dykstra \& S. Parks (Eds.), Faith development and Fowler (pp. 1-12). Birmingham, AL: Religious Education Press.

Fischer, K. W., \& Bidell, T. R. (2006). Dynamic development of action and thought. In W. Damon \& R. M. Lerner (Eds.), Handbook of child psychology (6 $6^{\text {th }}$ edn.). Volume one: Theoretical models of human development (pp. 313-399). Hoboken, NJ: John Wiley.

Fowler, J. W. (1981). Stages of faith: The psychology of human development and the quest for meaning. San Francisco, CA: Harper and Row.

Fowler, J. W. (1986). Faith and the structuring of meaning. In C. Dykstra \& S. Parks (Eds.), Faith development and Fowler (pp. 15-42). Birmingham, AL: Religious Education Press.

Fowler, J. W. (1987). Faith development and pastoral care. Philadelphia, PA: Fortress Press.

Fowler, J. W. (1992). Foreword. In J. Astley \& L. Francis (Eds.), Christian perspectives on faith development (pp. ix-xv). Leominster: Gracewing.

Fowler, J. W. (1995). Stages of faith: The psychology of human development and the quest for meaning. San Francisco, CA: Harper and Row.

Fowler, J. W. (1996). Faithful change: The personal and public challenges of postmodern life. Nashville, TN: Abingdon Press.

Fowler, J. W. (2000). Stufen des Glaubens: Die Psychologie der menschlichen Entwicklung und die Suche nach Sinn. Gütersloh: Kaiser. 
Fowler, J. W. (2001). Faith development theory and the postmodern challenges. International Journal for the Psychology of Religion, 11, 159-172.

Fowler, J. W. (2004). Faith development at 30: Naming the challenges of faith in a new millennium. Religious Education, 99, 405-421.

Fowler, J. W., Nipkow, K. E., \& Schweitzer, F. (Eds.) (1991). Stages of faith and religious development: Implications for church, education, and society. London: SCM Press.

Gellner, E. (1992). Postmodernism, reason and religion. London: Routledge.

Gergen, K. J. (2001). Psychological science in a postmodern context. American Psychologist, $56,803-813$.

Gilligan, C. (1982). In a different voice: Psychological theory and women's development. Cambridge, MA: Harvard University Press.

Goldman, R. (1964). Religious thinking from childhood to adolescence. New York: Seabury Press.

Gollnick, J. (2005). Religion and spirituality in the life cycle. New York: Peter Lang.

Grenz, S. J. (1996). A primer on postmodernism. Grand Rapids, MI: Eerdmans.

Hamrick, T. R. (1988). Transitional factors in the faith development of middle adults. Unpublished PhD thesis: University of Georgia.

Harris, M. (1989). Dance of the Spirit: The seven steps of women's spirituality. New York: Bantam.

Heywood, D. (2008). Faith development theory: A case for paradigm change. Journal of Beliefs \& Values, 29, 263-272. 
Jaspal, R., \& Cinnirella, M. (2010). Coping with potentially incompatible identities: Accounts of religious, ethnic, and sexual identities from British Pakistani men who identify as Muslim and gay. British Journal of Social Psychology, 49, 849-870.

Levinson, D. (1978). The seasons of a man's life. New York: Knopf.

Lyotard, J. F. (1984). The postmodern condition: A report on knowledge. Manchester: Manchester University Press.

McDargh, J. (2001). Faith development theory and the postmodern problem of foundations. International Journal for the Psychology of Religion, 11, 185-199.

Miller, P. H. (2002). Theories of developmental psychology (4 ${ }^{\text {th }}$ edn.). New York: Worth.

Moseley, R. M., Jarvis, D., \& Fowler, J. W. (1993). 1993 manual for faith development research. Atlanta, GA: Center for Research in Faith and Moral Development.

Nelson, C. E., \& Aleshire, D. (1986). Research in faith development. In C. Dykstra \& S. Parks (Eds.), Faith development and Fowler (pp. 180-201). Birmingham, AL: Religious Education Press.

Niebuhr, H. R. (1960). Radical monotheism and Western culture. New York: Harper and Row.

Oser, F., \& Gmünder, P. (1991). Religious judgement: A developmental approach. Birmingham, AL: Religious Education Press.

Paloutzian, R. F. (2005). Religious conversion and spiritual transformation: A meaningsystem analysis. In R. F. Paloutzian \& C. L. Park (Eds.), Handbook of the psychology of religion and spirituality (pp. 331-347). New York: Guilford Press. 
Reich, K. H. (2003). The person-God relationship: A dynamic model. International Journal for the Psychology of Religion, 13, 229-247.

Reich, K. H. (2005). Stage-structural approach to religious development. In E. M. Dowling \& W. G. Scarlett (Eds.), Encyclopedia of spiritual and religious development in childhood and adolescence (pp. 431-437). Thousand Oaks, CA: Sage.

Reich, K. H. (2008). Extending the psychology of religion: A call for exploration of psychological universals, more inclusive approaches, and comprehensive models. Archive for the Psychology of Religion, 30, 115-134.

Rizzuto, A.-M. (2001). Religious development beyond the modern paradigm discussion: The psychoanalytic point of view. International Journal for the Psychology of Religion, $11,201-214$.

Slee, N. M. (1996). Further on from Fowler: Post-Fowler faith development research. In L. J. Francis, W. K. Kay \& W. S. Campbell (Eds.), Research in religious education (pp. 73-96). Leominster: Gracewing.

Slee, N. (2004). Women's faith development: Patterns and processes. Aldershot: Ashgate.

Streib, H. (2001a). The symposium on Faith Development Theory and the modern paradigm. International Journal for the Psychology of Religion, 11, 141-142.

Streib, H. (2001b). Faith development theory revisited: The religious styles perspective. International Journal for the Psychology of Religion, 11, 143-158.

Streib, H. (2002). Faith development at 20 years. In R. Osmer \& F. Schweitzer (Eds.), Faith development and public life (pp. 2-20). St Louis, MO: Chalice Press. 
Streib, H. (2004). Extending our vision of developmental growth and engaging in empirical scrutiny: Proposals for the future of faith development theory. Religious Education, 99, 427-434.

Streib, H. (2005). Faith development research revisited: Accounting for diversity in structure, content, and narrativity of faith. International Journal for the Psychology of Religion, $15,99-121$.

Vuyk, R. (1981). Overview and critique of Piaget's genetic epistemology, 1965-1980: Volume 1. London: Academic Press.

Wilkinson, S., \& Kitzinger, C. (Eds.) (1996). Representing the Other: A 'Feminism \& Psychology' reader. London: Sage. 